\title{
Pleural Infection, CTCAE
}

National Cancer Institute

\section{Source}

National Cancer Institute. Pleural Infection, CT CAE. NCI Thesaurus. Code C143766.

A disorder characterized by an infectious process involving the pleura. 